\title{
Influence of Carbon Dioxide on the Energetics of Cerium Oxide Surfaces and Nanoparticle Morphology
}

\author{
Adam R. Symington, ${ }^{* \dagger}$ Robert M. Harker, ${ }^{\ddagger}$ Mark T. Storr,, Marco Molinari, \\ and Stephen C. Parker, \\ $\dagger$ Department of Chemistry, University of Bath, Claverton Down, Bath BA2 7AY, UK \\ $\ddagger A W E$ Aldermaston, Reading, $R G 74 P R, U K$ \\ IDepartment of Chemistry, University of Huddersfield, Queensgate, Huddersfield HD1 \\ 3DH, UK \\ E-mail: A.R.Symington@bath.ac.uk; S.C.Parker@bath.ac.uk
}

\begin{abstract}
Characterising and developing new catalytic materials for the adsorption and activation of $\mathrm{CO}_{2}$ is arguably one of the most important materials problems in recent times, with the realisation that climate change is upon us. In this paper we demonstrate, using electronic structure calculations, the difference in surface behaviour of the important catalyst ceria $\left(\mathrm{CeO}_{2}\right)$. Many nanoparticles show enhanced catalytic activity on particular surfaces. Hence, a key challenge is to identify strategies to control the expression of such surfaces and to avoid their disappearance over time. Here, we use density functional theory to explore the adsorption of carbon dioxide on the surfaces of cerium oxide $\left(\mathrm{CeO}_{2}\right)$, and its relationship with the resulting nanoparticle morphology under conditions of pressure and temperature. $\mathrm{CeO}_{2}$ is an important solid electrolyte in fuel cells, a catalyst, and enzyme mimetic agent in biomedicine, and has been shown
\end{abstract}


to interact strongly with $\mathrm{CO}_{2}$. We demonstrate that the adsorption of $\mathrm{CO}_{2}$ as a carbonate ion is energetically favorable on the $\{111\},\{110\}$ and $\{100\}$ surfaces of $\mathrm{CeO}_{2}$, and that the strength of this interaction is morphology and surface stoichiometry dependent. By predicting the surface stability as a function of temperature and pressure, we built surface phase diagrams and predict the surface dependent desorption temperatures of $\mathrm{CO}_{2}$. These temperatures of desorption follow the order $\{100\}>\{110\}>$ $\{111\}$ and are higher for surfaces containing oxygen vacancies compared to stoichiometric surfaces, indicating that surface oxidation processes can reduce the stability of surface carbonate groups. Finally, we propose a thermodynamic strategy to predict the evolution of nanoparticle morphology in the presence of $\mathrm{CO}_{2}$ as the external conditions of temperature and pressure change. We show that there is a thermodynamic driving force dependent on $\mathrm{CO}_{2}$ adsorption that should be considered when selecting nanoparticle morphologies in catalytic applications.

\section{Introduction}

The issue of global warming caused by anthropogenic $\mathrm{CO}_{2}$ has brought attention to atmospheric $\mathrm{CO}_{2}$ levels. ${ }^{1,2}$ Removal of $\mathrm{CO}_{2}$ from the atmosphere has the potential to reduce its

environmental impact but also to utilize the carbon in production of useful chemicals. ${ }^{3,4}$ Catalytically activated $\mathrm{CO}_{2}$ conversion provides a route to this goal but the activation of such a stable molecule poses energy related challenges: i.e. the use of high temperatures in the catalytic processes. The design and engineering of catalyst based materials is therefore of primary importance for realizing optimal and efficient $\mathrm{CO}_{2}$ conversion.

The first step of materials coming into contact with $\mathrm{CO}_{2}$ is that of adsorption. This adsorption needs to be understood since it is the first step towards addressing $\mathrm{CO}_{2}$ conversion. Here, the bonding of $\mathrm{CO}_{2}$ at the surface becomes an opportunity for control as it defines the activation of the molecule towards further reactions. Nevertheless, there are challenges to overcome, such as the formation of surface - carbonate species, alterations to the particle 
morphology and removal of $\mathrm{CO}_{2}$ from the surface.

The formation of surface species by adsorption of $\mathrm{CO}_{2}$ is observed on many oxides, e.g. Yttria stabilized Zirconia (YSZ), ${ }^{5} \mathrm{ZrO}_{2},{ }^{5} \mathrm{MgO},{ }^{6} \mathrm{BaTiO}_{3},{ }^{7} \mathrm{TiO}_{2},{ }^{8-11} \mathrm{Fe}_{2} \mathrm{O}_{3}{ }^{12-14}$ and $\mathrm{Al}_{2} \mathrm{O}_{3} .{ }^{15}$ Chemisorption of $\mathrm{CO}_{2}$ onto oxides is particularly prevalent where the oxides are basic ${ }^{16}$ and lead to a) carbonates through binding of the carbon atom to basic surface oxygen sites, and b) hydrogen carbonates where the $\mathrm{CO}_{2}$ inserts into an existing hydroxyl O-H bond. Formation of carboxylates (where the $\mathrm{CO}_{2}$ binds through oxygen to a metal atom) are less common but examples can be seen in the $\mathrm{ZnO}$ literature where both carboxylates and carbonates are observed. ${ }^{17}$ Of particular interest is cerium oxide (ceria, $\mathrm{CeO}_{2}$ ) due to the wide range of applications that result in direct contact between its surfaces and $\mathrm{CO}_{2} \cdot{ }^{18,19} \mathrm{CeO}_{2}$ is used in both three way catalysts and soot oxidation catalysts, ${ }^{20,21}$ where it oxidizes unburnt hydrocarbons and oxidizes $\mathrm{CO}$ to $\mathrm{CO}_{2} \cdot \mathrm{CeO}_{2}$ is used in the water gas shift reaction, ${ }^{22,23}$ where $\mathrm{H}_{2} \mathrm{O}+\mathrm{CO}>\mathrm{H}_{2}+\mathrm{CO}_{2}$. The dry reforming process is another application ${ }^{24,25}$ where the interaction between the surface and the gas is a conceivable way to provide an oxidant for organic reactions and would yield CO as a syngas for further synthesis. All these applications hold the key to understanding and defining a wider picture of the interaction of $\mathrm{CO}_{2}$ with $\mathrm{CeO}_{2}$.

In this context, we provide a computational analysis of the interaction of $\mathrm{CO}_{2}$ with the surfaces of $\mathrm{CeO}_{2}$ with the aim of defining a relationship between the adsorption of $\mathrm{CO}_{2}$ at $\mathrm{CeO}_{2}$ surfaces and the morphology of the nanoparticle. The driving force is to provide a computational procedure that could help design functionalized ceria morphologies as a function of pressure and temperature, two variables that can be controlled experimentally. We focus on the formation of carbonate species at the surfaces of ceria and discuss this in terms of adsorption strength, concentration and surface morphology effects. Although $\mathrm{CO}_{2}$ adsorption at the surfaces of ceria has been studied, the nature of surface intermediates has not been fully explored. In some cases it has been reported that surface carbonates are responsible for 
the reduction in the activity of ceria surfaces in several catalytic processes, ${ }^{26-29}$ i.e. carbonate poisoning. Both experimental and computational work have confirmed that carbonate species can form at the surface, ${ }^{30,31}$ but findings seems to be somehow complicated by the claims of a morphology dependent effect. Overbury et al. found for 'surface engineered' $\mathrm{CeO}_{2}$ nanoparticles that there was a clear dependence for the strength and amount of surface basic (both basic hydroxyls and surface lattice oxygen sites) on the particular surface on the particles. ${ }^{32}$ This change in the surface basicity was evident in differences between the IR spectra of $\mathrm{CO}_{2}$ adsorbed to these surfaces and the subsequent Temperature Programmed Desorption (TPD) experiments.

In this work we study the interaction of associatively adsorbed carbon dioxide molecules (carbonate $\mathrm{CO}_{3}{ }^{2-}$ species i.e. a bond forming between a surface oxygen atom and a $\mathrm{CO}_{2}$ molecule) with the most important low index surfaces of $\mathrm{CeO}_{2}(\{111\},\{110\}$ and $\{100\})$. We also investigate the adsorption of $\mathrm{CO}_{2}$ onto sub stoichiometric surfaces (surfaces containing an oxygen vacancy) of $\mathrm{CeO}_{2}$. We explore the morphology dependent impact on carbonate stability and demonstrate that the carbonates have significant effects relating to the morphology which can affect the catalytic properties of the material.

\section{Methodology}

\section{Adsorption of $\mathrm{CO}_{2}$ on Ceria Surfaces}

The number of potential configurations for adsorbed carbon dioxide on surfaces of ceria is extremely large and many have been proposed in the literature. ${ }^{33}$ We have studied the associative adsorption of $\mathrm{CO}_{2}$ on the surfaces of ceria (Figure 1) i.e. $\mathrm{CO}_{2}$ molecules adsorbed through a surface oxygen to form a carbonate $\left(\mathrm{CO}_{3}{ }^{2-}\right)$ species. We have also studied substoichiometric surfaces of ceria, here, an oxygen vacancy is introduced, which leaves two

electrons that localize and reduce two cerium atoms from $\mathrm{Ce}^{4+}$ to $\mathrm{Ce}^{3+}$; these surfaces are referred to as reduced surfaces in this article. For reduced surfaces, configurations were 
constructed to ensure that a $\mathrm{CO}_{2}$ oxygen fills the vacancy (Figure 1b). In some configurations where a carbonate was set at the start of the calculation, the surface oxygen-carbon bond was found to break but the $\mathrm{CO}_{2}$ molecule remained loosely bound to the surface: these configurations are referred to as 'molecular $\mathrm{CO}_{2}$ ' in this paper.
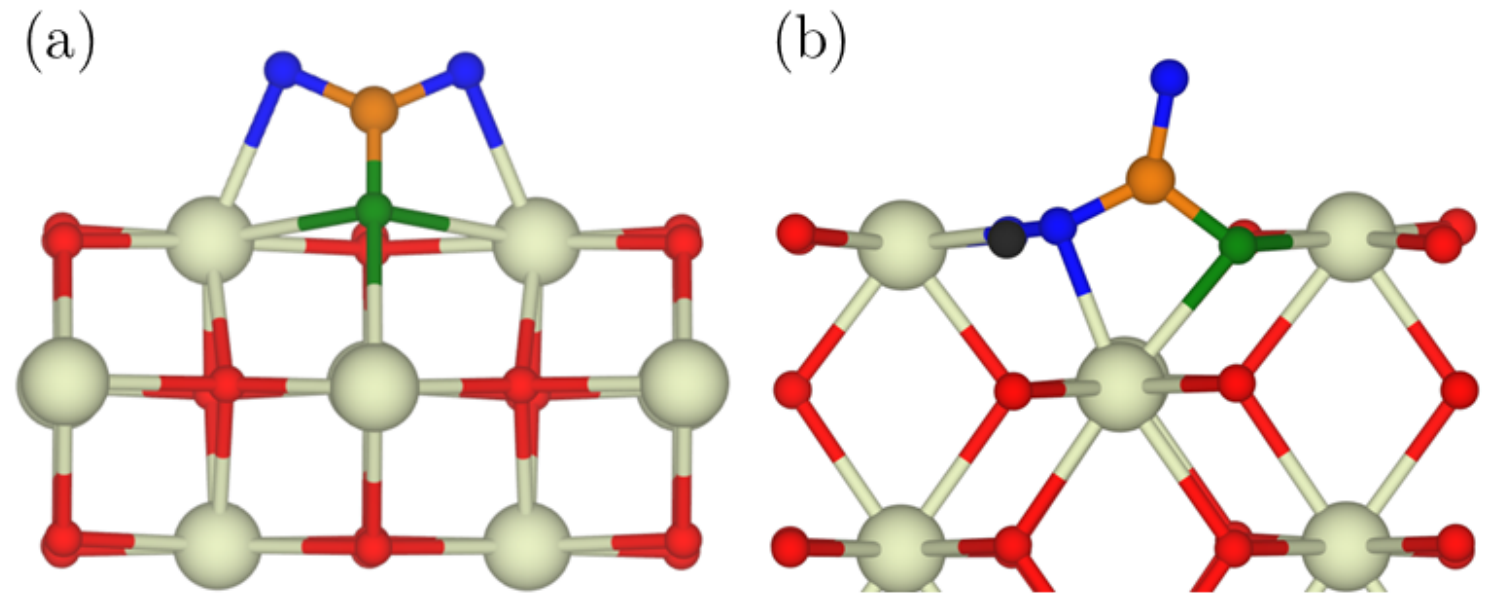

Figure 1: Schematic illustrating associative adsorption on stoichiometric (a) and reduced (b) $\{110\}$ surface of ceria. For clarity, oxygen, cerium, carbon, oxygen vacancies are shown in red, cream, orange and black respectively. The oxygen of the $\mathrm{CO}_{2}$ molecule are shown in blue and the surface oxygen that the carbon bonds to is shown in green.

In order to investigate the adsorption geometry, four concentrations of $\mathrm{CO}_{2}$ were investigated: $0.13,0.25,0.38$ and $0.51 \mathrm{CO}_{2} / \mathrm{nm}^{2}$ on the $\{111\} ; 0.12,0.23,0.35$ and $0.47 \mathrm{CO}_{2} / \mathrm{nm}^{2}$ on the $\{110\}$; and $0.17,0.33,0.50$ and $0.67 \mathrm{CO}_{2} / \mathrm{nm}^{2}$ on the $\{100\}$. These concentrations correspond to $1,2,3$ and $4 \mathrm{CO}_{2}$ species on each surface. In each case, different adsorption geometries were investigated and corresponded to monodentate, bidentate and tridentate adsorption configurations. In reality, hydroxyls/water will also exist at these surfaces and thus an interaction of these species with carbon dioxide is likely. Temperature Programmed Desorption experiments have shown that the stability of water and carbon dioxide on these surfaces is not identical and that carbon dioxide adsorbed as a carbonate can persist in the absence of water. ${ }^{34-37} \mathrm{~A}$ study on the co-sorption of water and carbon dioxide represents a possible future avenue of research. 


\section{Calculation Details}

Density functional theory (DFT) calculations were performed using the Vienna Ab-initio

Simulation Package (VASP) code, ${ }^{38,39}$ within which projector augmented-wave pseudopotentials and a plane wave cutoff of $500 \mathrm{eV}$ was used with the sampling of the Brillouin zone sampled using a $5 \times 5 \times 5$ Monkhorst-Pack grid for the bulk materials $\left(\mathrm{CeO}_{2}\right.$ and $\left.\mathrm{Ce}_{2} \mathrm{O}_{3}\right)$ and 2x2x1 for the slabs. Calculations were carried out using the generalized gradient approximation (GGA) exchange-correlation functional of Perdew (PBE), with the $+\mathrm{U}$ correction of Dudarev $^{40}$ to account for on-site Coulombic interactions. A U value of $5 \mathrm{eV}$ is applied to Ce $\mathrm{f}$ states as this value has been utilized successfully in other studies. ${ }^{30,41,42}$ The structures were optimized until the residual forces on each atom were less than $10 \mathrm{meV} \AA^{-1}$. All calculations were spin polarized and an initial ferromagnetic ordering was used throughout, which was shown to produce no difference in the energetic of $\mathrm{CeO}_{2}$ systems. ${ }^{43}$

\section{Bulk Models}

The structure of stoichiometric bulk $\mathrm{CeO}_{2}$ retains the fluorite crystal structure (space group Fm-3m) despite a small expansion of the unit cell, which is well-documented effect for the ab initio methodology employed in this study. ${ }^{43}$ The simulated lattice parameter $(\mathrm{a}=0.545 \mathrm{~nm})$ compares well with the experimental lattice parameter of $(a=0.541 \mathrm{~nm}) .{ }^{44}$

\section{Surface Models}

Model surface structures were generated using the METADISE code. ${ }^{45}$ 3D boundary conditions were used throughout, and hence, the surfaces were modelled using the slab method ${ }^{46}$ in which a finite number of crystal layers is used to generate two identical surfaces via the introduction of a vacuum gap perpendicular to the surface. A vacuum gap of $15 \AA$ was used to minimize the interaction between images. The $\{100\}$ and $\{110\}$ slabs with a $\mathrm{p}(2 \times 2)$ expansion of the surface unit cell included 13 and 7 atomic layers $\left(24\right.$ and $28 \mathrm{CeO}_{2}$ units, 
respectively), while the $\{111\}$ slab with a $\mathrm{p}(2 \times 3)$ expansion included 12 atomic layers (24 $\mathrm{CeO}_{2}$ units).

The K-point grid of $\Gamma$-centred 2x2x1 with the third vector perpendicular to the surface plane was used and deemed converged.

\section{Surface Energies and Thermodynamic Framework}

Using the slab method, the surface energy $\left(\gamma_{\text {bare }}\right)$ can be calculated from the energy of the systems containing the slab $\left(E_{\text {slab-bare }}\right)$ the energy of ceria stoichiometric bulk $\left(E_{b u l k-\mathrm{CeO}_{2}}\right)$ and the surface area $(S)$, according to eq 1 .

$$
\gamma_{\text {bare }}=\frac{E_{\text {slab-bare }}-E_{\text {bulk-CeO}}}{2 S}
$$

The calculated surface energy for the $\{111\},\{110\}$ and $\{100\}$ was $0.67,1.05$ and $1.41 \mathrm{Jm}^{-2}$ respectively. This is in agreement with previous computational work. ${ }^{41,47,48}$ The surface energy for the reduced surface was calculated according to

$$
\gamma_{\text {slab-reduced }}=\frac{E_{\text {slab-bare }}-E_{\text {bulk-CeO}}+E_{b u l k-C e_{2} \mathrm{O}_{3}}}{2 S}
$$

where $\gamma_{\text {slab-reduced }}$ is the energy of the reduced slab and $E_{b u l k-C e_{2} O_{3}}$ is the energy bulk bixbyite $\mathrm{Ce}_{2} \mathrm{O}_{3}$.

Equations 1 and 2 provide the surface energy at $0 \mathrm{~K}$ and these are not representative of the operating conditions of various catalytic process, and the synthesis and sintering conditions. Surface energies for the carbonated surfaces at specific temperature and pressures $\left(\gamma_{C O_{2}, T, p}\right)$ were calculated with the addition of temperature as follows ${ }^{41,42,49}$

$$
\gamma_{C O_{2}, T, p}=\gamma_{\text {Bare }}+\left(C\left(E_{a d s, T}-R T \ln \left(\frac{p_{C O_{2}}}{p^{o}}\right)\right)\right)
$$


where $\mathrm{C}$ is the coverage of carbon dioxide,

$$
E_{a d s, T}=E_{\text {slab }, C O_{2}}-\left(E_{\text {slab,bare }}+n_{C_{2}} E_{C_{2},(T)}\right) / n_{C O_{2}}
$$

where $E_{s l a b, \mathrm{CO}_{2}}$ is the energy of the slab with the adsorbed species, $n_{\mathrm{CO}_{2}}$ is the number of adsorbed $\mathrm{CO}_{2}$ molecules,

$$
E_{C O_{2},(T)}=E_{C O_{2},(0 K, g)}-T S_{(T)}
$$

where $S_{(T)}$ is the experimental entropy of gaseous carbon dioxide in the standard state.

Crystal morphologies were generated based on the surface energies calculated with equation 3 and constructed with a Wulff construction. The surface area of each surface as a function of temperature and pressure was calculated from the Wulff construction and these values were combined to give the surface area ratio between all surfaces under certain temperature and pressure.

Analysis was conducted using the surfinpy code. ${ }^{50}$ Wulff constructions were generated using the pymatgen code $^{51}$ and all figures were drawn using VESTA. ${ }^{52}$

\section{Results and Discussion}

\subsection{Adsorption Geometry}

At the lowest concentration of $\mathrm{CO}_{2}$, tridentate adsorption is favoured on all surfaces, however there are slight differences between the $\{100\}$ and the $\{110\} /\{111\}$ surfaces. On the $\{100\}$ surface the carbonate ion lies flat, with each of the three oxygen bridging between two or three surface cerium atoms. This arrangement is in agreement with Albrecht et al. who studied carbonate at the $\{100\}$ surface and found that $\mathrm{CO}_{3}{ }^{2-}$ exists as a flat lying, tridentate 
species. ${ }^{37}$ The surface oxygen rearranges slightly to accommodate the carbonate (Figure $2 a)$. The rearrangement of the $\{100\}$ oxygen sub-lattice has been reported in other studies of polyanion adsorption, e.g. phosphates. ${ }^{47}$ In contrast on the $\{110\}$ and $\{111\}$ surfaces a carbonate sits more upright (Figure $2 \mathrm{~b} / \mathrm{c}$ ). The adsorption geometry on the $\{111\}$ surface is in agreement with Hahn et $\mathrm{al}^{30}$

(a)

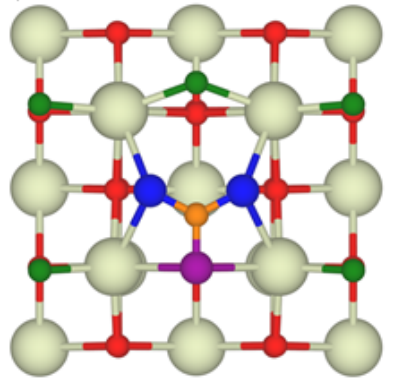

(d)

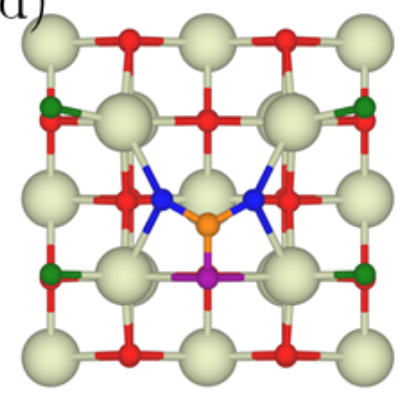

(b)

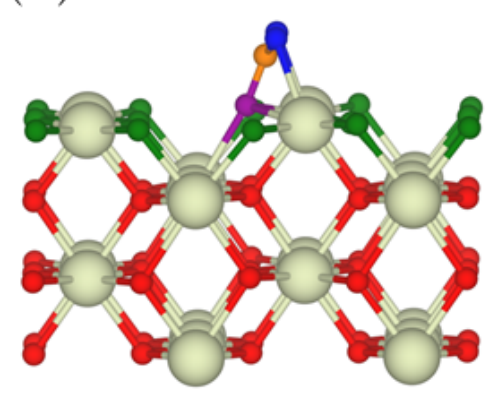

(e)

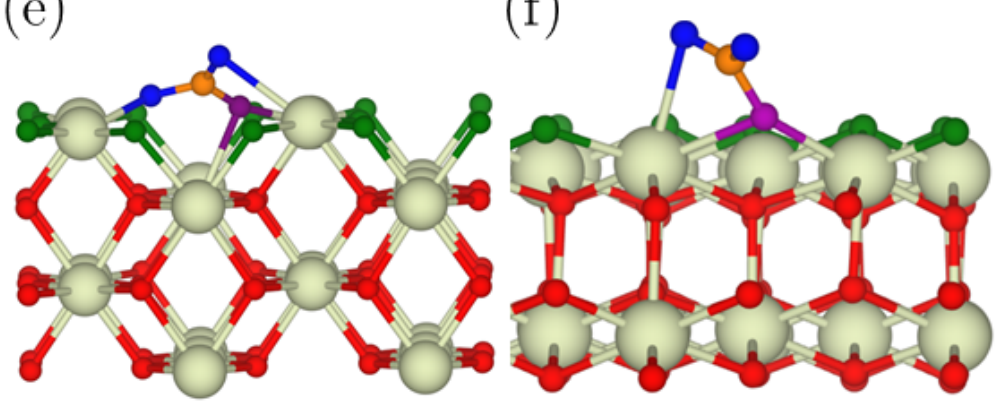

Figure 2: Adsorption geometry for a single carbonate molecule on the stoichiometric $\{100\}$, $\{110\}$ and $\{111\}$ (a, b, c) and reduced $\{100\},\{110\}$ and $\{111\}$ (d,e,f) surfaces. The $\{100\}$ surface is shown from above the surface plane and the $\{110\}$ and $\{111\}$ surfaces are shown from the side. For clarity, cerium, oxygen, surface oxygen and carbon atoms are displayed in cream, red, green and orange. Oxygen from the $\mathrm{CO}_{2}$ molecule are shown in blue and the surface oxygen bonded to the $\mathrm{CO}_{2}$ molecule is shown in purple.

Tridentate adsorption geometry is favoured at the two lowest $\mathrm{CO}_{2}$ concentrations (Figure 2) whereas a mixture of adsorption geometries becomes favoured at higher $\mathrm{CO}_{2}$ concentrations as steric effects between molecules become important. This sheds light on the proposition that carbonates exist either as a mixture of flat lying and upright, slightly tilted, or that the entire carbonate population is lying flat. ${ }^{37}$ Our results indicate that at high concentra- 
tions the carbonates will exist as a mixture of tilted and flat lying carbonates, but at low concentrations the entire population is flat lying.

On the $\{110\}$ and $\{100\}$ surfaces all carbonates remain as $\mathrm{CO}_{3}{ }^{2-}$ species whereas on the $\{111\}$ surface at the highest concentration $\left(0.51 \mathrm{CO}_{2} / \mathrm{nm}^{2}\right)$ there is a mixture of molecularly adsorbed $\mathrm{CO}_{2}$ and carbonate species $\left(\mathrm{CO}_{3}{ }^{2-}\right)$. This is in agreement with Hahn et al., who predicted that at higher concentrations of $\mathrm{CO}_{2}$ there are chains of physisorbed $\mathrm{CO}_{2}$ molecules as opposed to chemisorbed $\mathrm{CO}_{3}{ }^{2-} \cdot{ }^{30}$

On the reduced surfaces the most stable configurations are those that maximize the surface coordination of the cerium atoms. It was found that some monodentate configurations switched geometry during the minimization to bidentate or tridentate, further indicating that the surface species will adsorb by promoting those configurations with higher surface coordination.

The average bond length between the carbonate oxygen and surface cerium atoms is smallest for monodentate adsorption configurations $(2.17 \AA)$ and longest for tridentate configurations $(2.5 \AA)$. This shows that the surface is capable of recovering its oxygen coordination by increasing the numbers of slightly weaker, longer bonds.

\subsection{Adsorption Energy}

The adsorption energy for $\mathrm{CO}_{2}$ on the stoichiometric and reduced surfaces as a function of $\mathrm{CO}_{2}$ concentration is shown in figure 3. The strength of the adsorption energy of $\mathrm{CO}_{2}$ follows the order $\{100\}>\{110\}>\{111\}$ at all concentrations for both the stoichiometric and reduced surfaces. The strength of the adsorption and order of stability of the adsorption energies can be explained by the coordination of surface cerium atoms. Cerium at the $\{111\}$ is 7 fold coordinated, whereas 6 fold coordinated on the $\{100\}$ and $\{110\}$. The stronger adsorption energies for the $\{110\}$ and $\{100\}$ surfaces is due to the surface cerium regaining coordination from 6 7/8 depending on the concentration of $\mathrm{CO}_{2}$. The Ce atoms at the $\{111\}$ 
surface are already 7 fold coordinated with respect to oxygen, and thus there is a smaller energetic gain in recovering the 8 fold coordination.

At the lowest coverage, the adsorption energy on the $\{111\}$ is $-0.53 \mathrm{eV}$, which is in good agreement (energetically and structurally) with that calculated by Hahn et al. ${ }^{30}$ Cheng et al. calculated the adsorption energy of $\mathrm{CO}_{2}$ on the $\{110\}$ surface and concluded that it was physisorbed as molecularly adsorbed $\mathrm{CO}_{2}$ and did not form a carbonate. ${ }^{31}$ This is in contrast to our results which find that $\mathrm{CO}_{2}$ will always spontaneously (i.e. the process is barrier-less) form a carbonate on the $\{110\}$ surface. ${ }^{31}$ The much stronger interaction between the $\{100\}$ and $\mathrm{CO}_{2}$ is supported by Albrecht et al. ${ }^{37}$ who calculated an adsorption energy for flat lying $\mathrm{CO}_{3}{ }^{2-}$ of $-1.93 \mathrm{eV}$, which is in good agreement with our calculated adsorption energy of $-1.87 \mathrm{eV}$.

The adsorption energy is more favourable for the reduced surfaces compared to the stoichiometric surfaces, this is because the reduction of $\mathrm{CeO}_{2}$ involves the removal of surface oxygen; this lowers the Ce coordination. $\mathrm{CO}_{3}{ }^{2-}$ species introduce two oxygen atoms to the surface, which increase the surface coordination of the cerium atoms and thus there is a strong bind. 


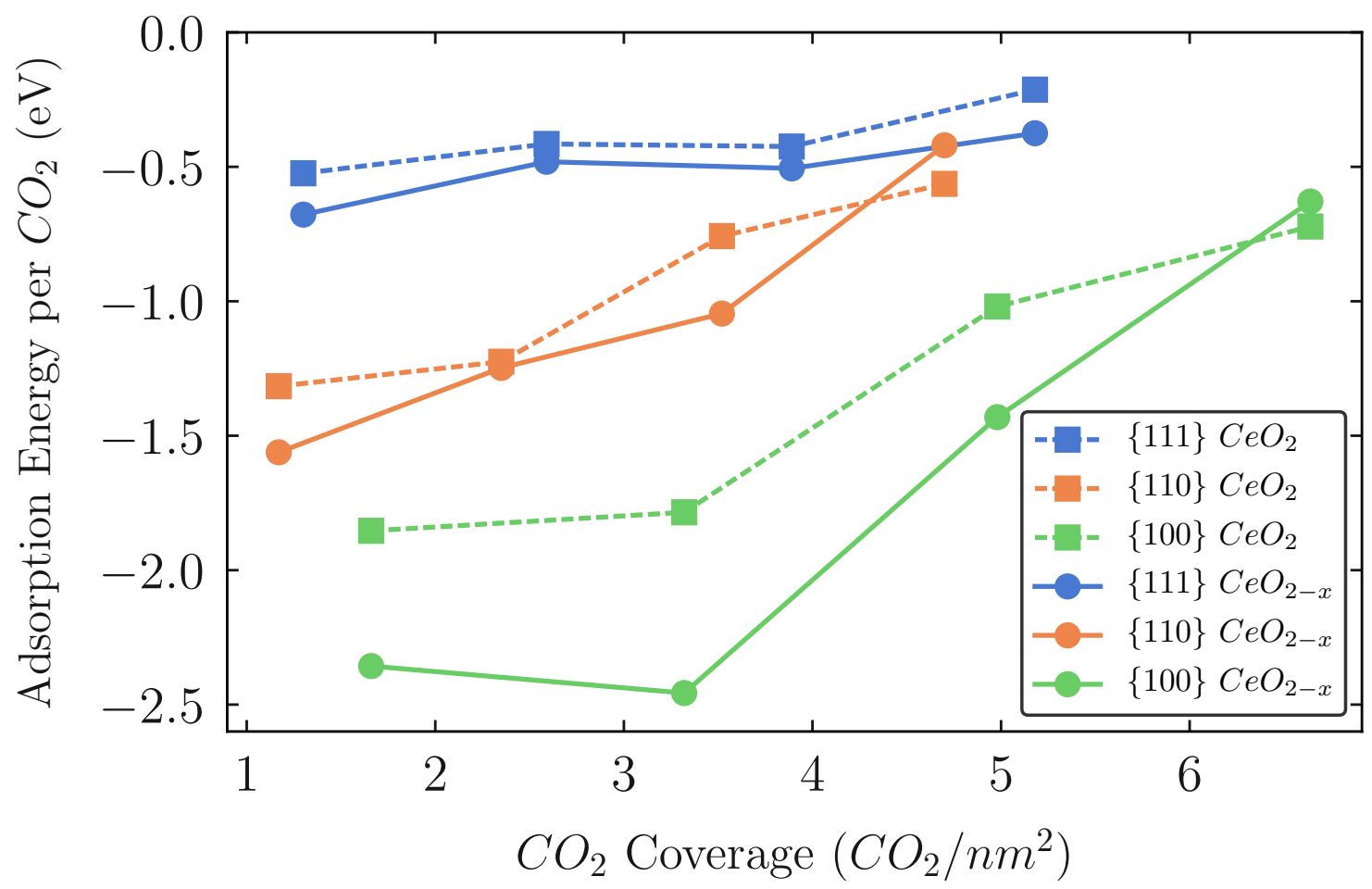

Figure 3: Adsorption energies for $\mathrm{CO}_{2}$ adsorbing as a carbonate molecule on the stoichiometric (dashed lines) and reduced (solid lines) low index $\mathrm{CeO}_{2}$ surfaces. The $\{111\},\{110\}$ and $\{100\}$ surfaces are shown in blue, orange and green.

\subsection{Surface Phase Diagrams}

To define ceria surface stability in the presence of adsorbed $\mathrm{CO}_{2}$, we have generated phase diagrams pressure of $\mathrm{CO}_{2}$ as a function of temperature for the $\{100\},\{110\}$ and $\{111\}$ surfaces of ceria according to Eq 3. This is a successful procedure used in other work, ${ }^{49,53,54}$ as well as on $\mathrm{CeO}_{2}{ }^{41}$ (Later verified experimentally ${ }^{34}$ ). Figure 4 shows the $\mathrm{P}$ vs $\mathrm{T}$ phase diagrams for each surface, where the different region of the diagrams represent the most stable surface composition (i.e. those with the lowest surface energy Eq 3 at those particular conditions of pressure and temperature.

On the stoichiometric surfaces, $\mathrm{CO}_{2}$ will desorb from the $\{111\}$ first, followed by the $\{110\}$ and then the $\{100\}$ at any given pressure (Figure 4 A,B,C). The introduction of oxygen vacancies greatly increases the temperature range that adsorbed carbonate is stable on the 
surfaces. This is due to the surface healing effect where $\mathrm{CO}_{3}{ }^{2-}$ species at the surface allow the surface cerium to regain their partial coordination (Figure $2 \mathrm{~d}$, e, f). As seen in section 3.1, the adsorption energies for 3 and 4 carbonate species are quite weak compared to 1 and 2 carbonate species, as a result the 3 and 4 carbonate phases do not appear in the phase diagram (with the exception of the reduced $\{110\}$ surfaces). At low $\mathrm{T}$ (blue region) the surfaces are partially covered with carbonate molecules, whereas at high $\mathrm{T}$ (red region) carbonate molecules are not stable at the surface and thus are not present.
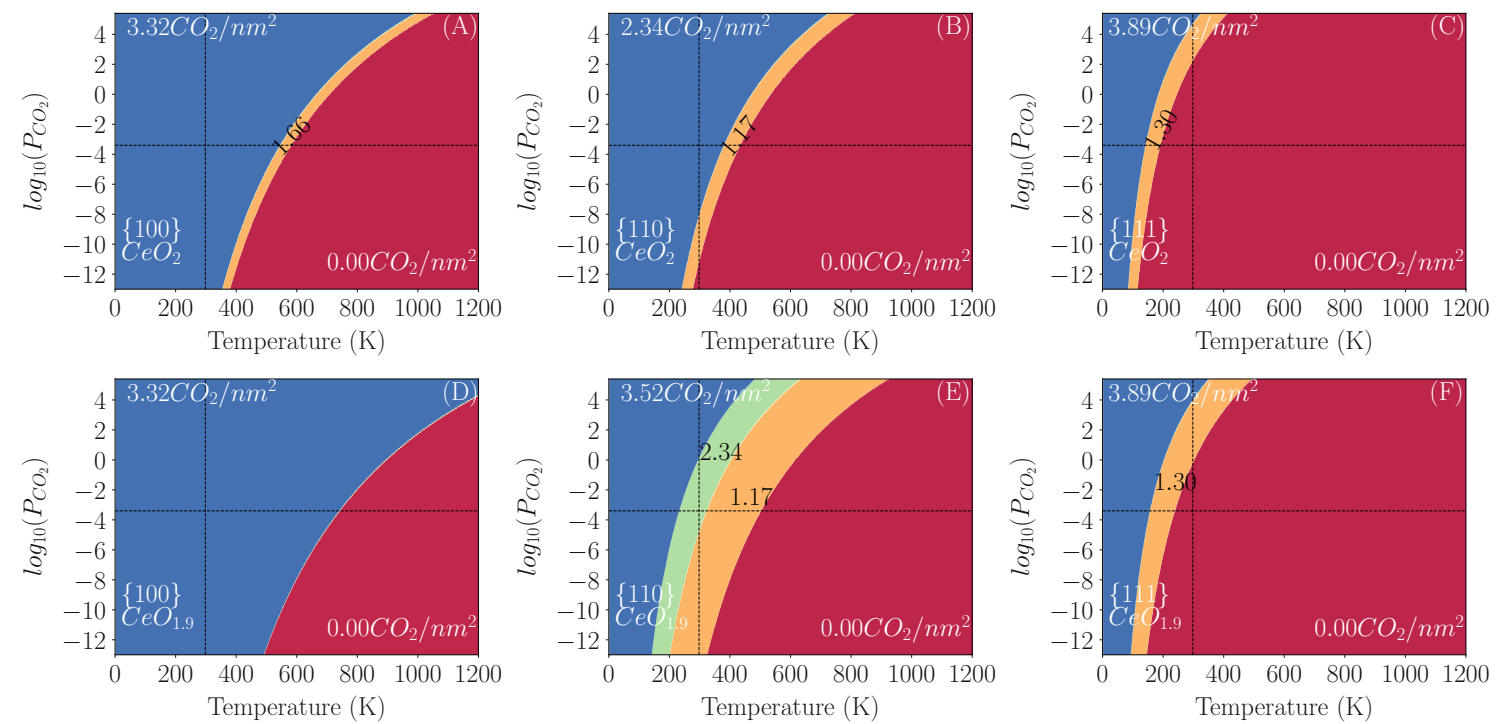

Figure 4: Pressure vs Temperature phase diagrams for the stoichiometric $\{100\}(\mathrm{A}),\{110\}$ (B), $\{111\}(\mathrm{C})$ and the reduced $\{100\}(\mathrm{D}),\{110\}(\mathrm{E})$ and $\{111\}(\mathrm{F})$ surfaces. The $\mathrm{CO}_{2}$ coverage $\left(\mathrm{CO}_{2} / \mathrm{nm}^{2}\right)$ of each phase is added to the phase diagram.

\subsection{Desorption Temperature}

Based upon the pressure vs temperature phase diagrams, we have calculated the temperature of desorption for carbonate species at the $\{111\},\{110\}$ and $\{100\}$ surfaces as a function of $\mathrm{CO}_{2}$ pressure (Figure 5). The desorption temperatures represent the transition between a bare surface and a surface with $\mathrm{CO}_{2}$ adsorbed as a carbonate. These can be compared to the experimental values measured via Temperature Programmed Desorption experiments for the low index surfaces of ceria. On all surfaces, we find that the carbonate is more stable 
on the reduced surface compared to the stoichiometric surface and we attribute this to the oxygen vacancy healing effect discussed in section 3.3.

Senanayake and Mullins reported weakly bound $\mathrm{CO}_{2}$ on the $\{111\}$, which start desorbing at $150 \mathrm{~K}$ with only a small amount of carbonate at $200 \mathrm{~K} .{ }^{33}$ Temperature Programmed Desorption experiments are typically run under UHV (10-12 bar) and within our model we predict the removal of $\mathrm{CO}_{2}$ at $127 \mathrm{~K}$ on the $\{111\}$ under these conditions. Removal of $\mathrm{CO}_{2}$ at low temperatures on the $\{111\}$ is also reported by Staudt et al who could not detect any $\mathrm{CO}_{2}$ on the $\{111\}$ surface at $300 \mathrm{~K} .{ }^{55}$ Also, Senanayake et al determined that carbonates were removed from the $\{111\}$ surface of $\mathrm{CeO}_{\mathrm{x}} / \mathrm{Au}$ on heating to $300 \mathrm{~K} .{ }^{36}$ These observations are consistent with our findings as only at high $\mathrm{CO}_{2}$ pressures we detect carbonates persisting beyond $300 \mathrm{~K}$.

Carbonate is bound much more strongly on the $\{100\}$ and thus the desorption temperatures are much higher (Figure 5). Albrecht et al. found that carbonate species on the $\{100\}$ are stable up to $600 \mathrm{~K}$ for stoichiometric ceria and $700 \mathrm{~K}$ for partially reduced ceria $\left(\mathrm{CeO}_{1.9}\right)$ under ultra-high vacuum conditions. ${ }^{37}$ We predict under these conditions that $\mathrm{CO}_{2}$ will desorb by $450 \mathrm{~K}$ on stoichiometric ceria and $550 \mathrm{~K}$ on reduced ceria. It is worth noting that our reduced ceria model is $\mathrm{CeO}_{1.916}$ which not as oxygen deficient as the experimental samples. Furthermore, we have only considered $\mathrm{CO}_{3}{ }^{2-}$ species at the surface and in reality, depending on the $\mathrm{pH}$, a wide range of carbonate species can exist and the distinction is not made in the experiments.

Our calculations suggest that oxidation of the surface removes / hinders the adsorption of carbonates from/to the surface, as the reduced surfaces have considerably higher desorption temperatures compared to stoichiometric surfaces (up to $200 \mathrm{~K}$ - Figure 5). Oxygen vacancies are reactive sites and are often desirable in catalytic reactions, however carbon dioxide interacts so strongly with the vacancies that the catalyst may lose its efficiency. It is clear that efficiency may be restored as the temperature increases (and $\mathrm{CO}_{2}$ desorbs). However, 
this comes at a higher cost as more energy is required to remove $\mathrm{CO}_{2}$ from reduced compared to stoichiometric surface. In the Water Gas Shift Reaction (WGSR) Feng et al., have shown that, for ceria, the redox reactions proceeds via a stable carbonate intermediate; the coverage of this intermediate is dependent on the surface $\mathrm{Ce}^{3+}$ concentration. ${ }^{56}$ We show that reduced surfaces have a considerably stronger interaction with carbonates compared to the stoichiometric surfaces (Figure 4/5) and given that $\mathrm{Ce}^{3+}$ concentration is dependent on the concentration of oxygen vacancies, we can infer that the experimental observations of Feng et al., is to be attributed to the strong interaction between $\mathrm{CO}_{2}$ and the oxygen vacancies.

Ceria based catalysts are also employed in the low temperature WGSR (500 $600 \mathrm{~K})$. This reaction is dependent on the formation of formates or carbonates at the surface which decompose into $\mathrm{CO}_{2}$ and $\mathrm{H}_{2} \cdot{ }^{18,23}$ Platinum $/ \mathrm{CeO}_{2}$ catalysts have been shown to suffer from deactivation as a result of fuel cell/fuel processor shutdowns and this has been linked to the formation of carbonates. The authors also showed a relationship between carbonate formation and removal of hydroxyl groups. ${ }^{20}$ Since hydroxyl groups are thought to be a key component of the reaction, and water dissociation is considerably stronger at oxygen vacancy sites, ${ }^{41}$ this a possible explanation for the deactivation: carbonate groups form a strong complex at the oxygen vacancy sites, blocking the reactive sites for water splitting to occur. 

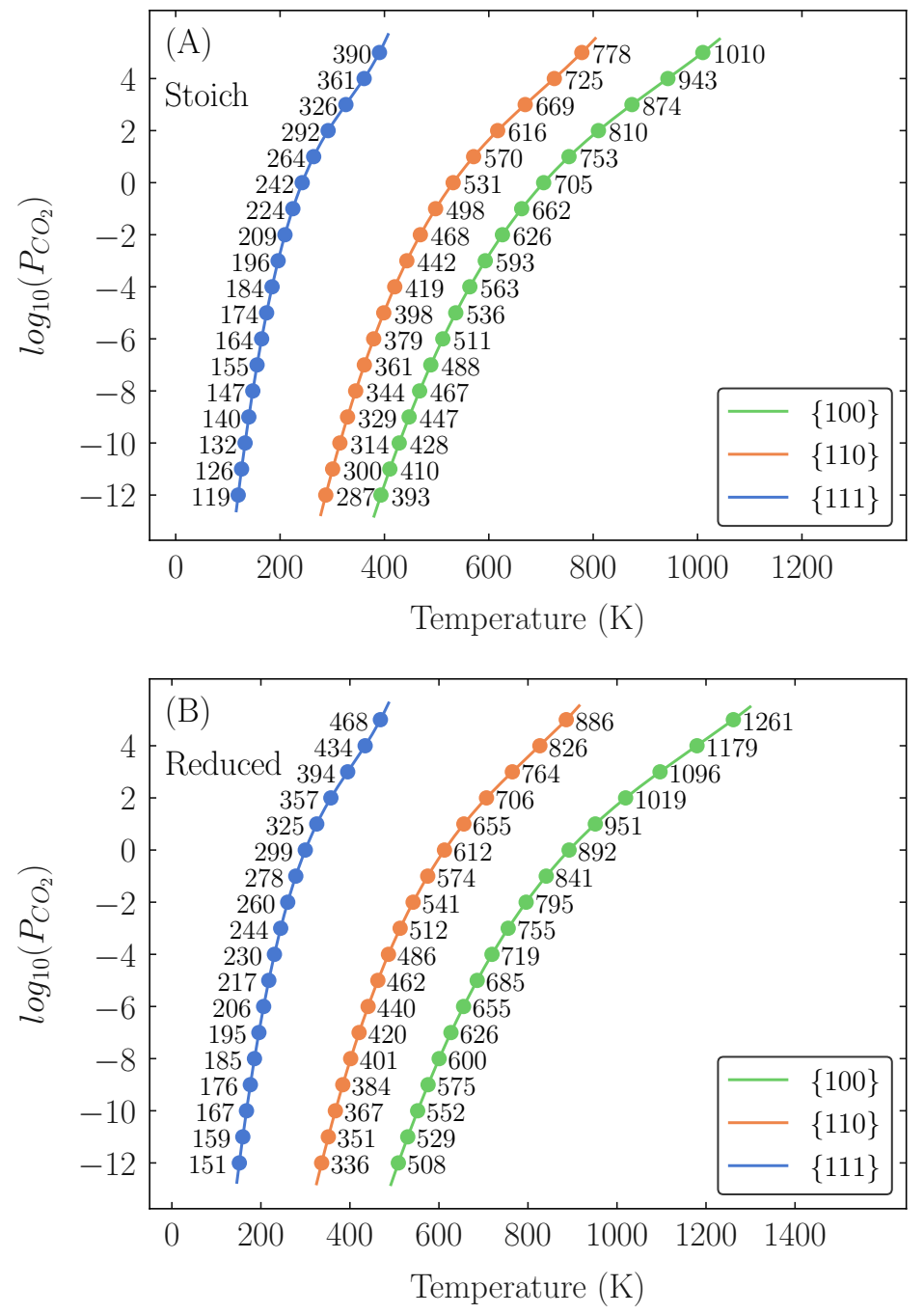

Figure 5: Temperature of desorption for the stoichiometric (A) and reduced (B) surfaces. The $\{111\},\{110\}$ and the $\{100\}$ surfaces are shown in blue, orange and green. The temperature of desorption at pressures ranging from -12 $\log _{10}\left(P_{\mathrm{CO}_{2}}\right)$ (bar) to $5 \log _{10}\left(P_{\mathrm{CO}_{2}}\right)$ (bar) in increments of 1 are marked at the corresponding locations on the plots.

\subsection{Predicted Particle Morphology}

The performance of nanoceria catalysts in the form of nanoparticles is influenced by the surface morphology, composition and stoichiometry of the exposed facets. ${ }^{18,57}$ Depending of the formation conditions a variety of structures can be formed with specific surfaces: cubes $\{100\}$, octahedra $\{111\}$ and rods (variously described as defected surfaces or a mixture of 
$\{110\}$ and $\{100\}) .{ }^{58}$ This has been shown in recent times, where research has focused on the effect of the different exposed facets on different catalytic processes. ${ }^{59-62}$ As individual catalytic application is optimized by a specific morphology, then it is important to reach the nanoparticle optimal design before implementing the material in the catalytic process. We have combined simple yet effective thermodynamic computational strategies that use the information on surface stability to generate nanoparticle morphologies as a function of experimentally tuneable conditions such as those of pressure and temperature.

Based upon the surface energies calculated in section 3.3, we have constructed Wulff plots as a function of temperature and pressure of $\mathrm{CO}_{2}$ for the stoichiometric and reduced surface systems in order to provide insight into whether $\mathrm{CO}_{2}$ can, from a thermodynamic point of view, alter the particle morphology (Figure 6). For clarity, figure 6 shows the thermodynamic driving force under certain conditions towards a certain morphology. The desorption temperature curves for each surface has been overlaid on to each plot. These illustrate the regions of the morphology phase diagram where each surface is being stabilized by carbonate species. For example, on stoichiometric surface the $\{111\}$ surface has very low desorption temperatures whereas the $\{100\}$ surface has comparatively high desorption temperatures, the region of the phase diagrams between these lines is the region where the surface energy of the $\{100\}$ is being lowered by carbonate species while the $\{111\}$ is not (this means that in this region the particle morphology the $\{100\}$ is covered in carbonates whereas the $\{111\}$ is not). This lowering of one surface energy relative to another is why adsorbed species are able to affect the morphology significantly. It is noted that higher temperatures may complicate the morphology phase diagrams: in $\mathrm{CO}_{2}$ the reduced surfaces may be oxidized and in vacuum oxygen can be extracted to reduce the surface. These additional complexities are not captured in these diagrams. 

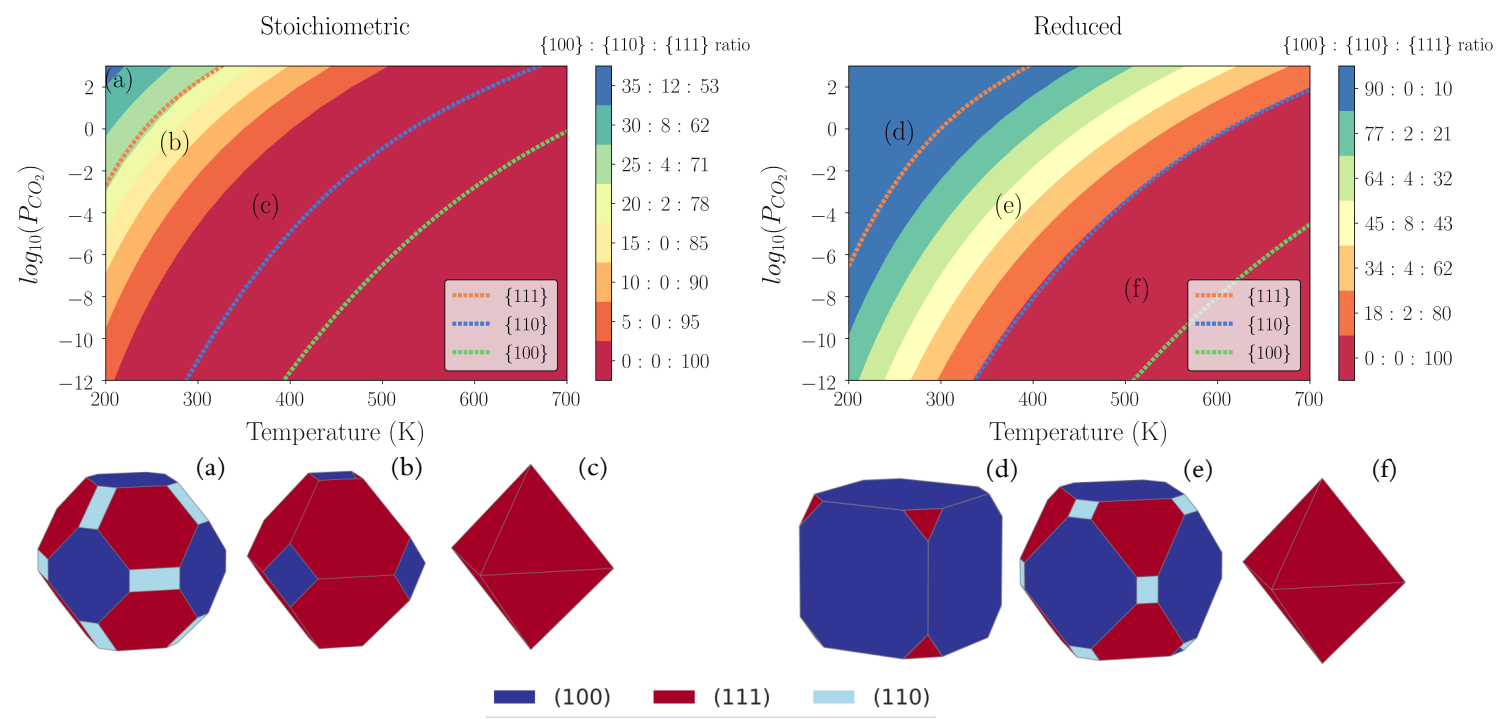

Figure 6: Particle morphology phase diagram for the stoichiometric and reduced surfaces. Wulff constructions are shown for the stoichiometric and reduced surfaces. These correspond to a $\{100\}:\{110\}:\{111\}$ ratio of 35:12:63 (a), 15:0:85 (b) and 0:0:100 (c) for the stoichiometric surface and 90:0:10 (d), 45:12:43 (e) and 0:0:100 (f) for the reduced surface. For clarify the $\{111\},\{110\}$ and $\{100\}$ facets are shown in red, light blue and dark blue respectively. The desorption temperatures for the $\{111\}$ (orange), $\{110\}$ (blue) and $\{100\}$ (green) are shown on each phase diagram to illustrate the regions where carbonates are stable and thus influencing the morphology.

Using ultra high vacuum conditions as a reference point (i.e. below $10^{-10} \log _{10}\left(P_{C O_{2}}\right)$ ), for stoichiometric ceria, there is a clear preference for octahedral nanoparticles at temperatures above $210 \mathrm{~K}$. However with increasing pressure, the nanoparticle area is increasingly made up of $\{100\}$ and $\{110\}$ surfaces. Using ultra high vacuum conditions as a reference point, for reduced surfaces octahedral nanoparticles are formed above $310 \mathrm{~K}$. High pressures of $\mathrm{CO}_{2}$, low temperatures and reduced ceria are a conceivable combination to generate highly reactive nanocubes. It is relatively nice to see that corners of nanocubes (Figure 6d) are truncated by $\{111\}$ surfaces; this seems to be in line with the findings that there is a minimum size of associated with this truncation. ${ }^{57}$ 


\section{Conclusions}

The effect of adsorbants on the surface chemistry of materials is important to fully understand the properties of many materials. In this study, we have studied the adsorption of $\mathrm{CO}_{2}$ molecules as surface carbonate $\left(\mathrm{CO}_{3}{ }^{2-}\right)$ species using density functional theory. The results reveal the following key features:

1. $\mathrm{CO}_{2}$ adsorbed as carbonate $\left(\mathrm{CO}_{3}{ }^{2-}\right)$ species are more stable on surfaces containing oxygen vacancies (reduced surfaces) than on stoichiometric surfaces due to a strong interaction with surface oxygen vacancies.

2. There is a morphology dependent adsorption with the adsorption strength following the order $\{100\}>\{110\}>\{111\}$.

3. The $\{111\}$ surface, in line with experimental evidence, desorbs surface carbonates at lower temperatures, whereas the $\{100\}$ surface retains adsorbed carbonates across a wider temperature range.

4. The high stability of carbonate species on the $\{100\}$ relative to the $\{111\}$ surface has a striking effect on the predicted morphology. Surfaces of $\{100\}$ are promoted over $\{111\}$ at lower temperatures and higher $\mathrm{CO}_{2}$ pressures, and $\{111\}$ surfaces are promoted over $\{100\}$ surfaces at higher temperatures and lower $\mathrm{CO}_{2}$ pressures.

The atomic-scale insights presented here provide insight on the interaction between carbon dioxide and surfaces of cerium oxide and generally applicable to a range of materials. Enhancing our fundamental understanding of surface chemistry in the presence of adsorbed molecules and their influence on catalytic processes is crucial for the future optimization of these processes. 


\section{Author Information}

\section{Corresponding Author}

* Adam R. Symington A.R.Symington@bath.ac.uk

* Stephen C. Parker - S.C.Parker@bath.ac.uk

\section{ORCID}

Adam R. Symington: 0000-0001-6059-497X

Marco Molinari: 0000-0001-7144-6075

Stephen C. Parker: 0000-0003-3804-0975

\section{Author Contributions}

ARS carried out the simulations, designed and carried out the data analysis, ARS, MM and SCP devised the study and ARS wrote the manuscript with contributions from all authors.

\section{Acknowledgement}

We would like acknowledge AWE and EPSRC (EP/P007821/1, EP/R010366/1, EP/R023603/1) for funding. Computations were run on Balena HPC facility at the University of Bath and the ARCHER UK National Supercomputing Service (http://www.archer.ac.uk) via our membership of the UKs HEC Materials Chemistry Consortium (HEC MCC) funded by EPSRC (EP/L000202, EP/R029431). 


\section{References}

(1) Tol, R. S. J. The Economic Impacts of Climate Change. Review of Environmental Economics and Policy 2018, 12, 4-25.

(2) Dickinson, R. E.; Cicerone, R. J. Future global warming from atmospheric trace gases. Nature 1986, 319, 109-115.

(3) Ma, J.; Sun, N.; Zhang, X.; Zhao, N.; Xiao, F.; Wei, W.; Sun, Y. A short review of catalysis for CO2 conversion. Catalysis Today 2009, 148, 221 - 231.

(4) Samanta, A.; Zhao, A.; Shimizu, G. K. H.; Sarkar, P.; Gupta, R. Post-Combustion CO2 Capture Using Solid Sorbents: A Review. Industrial \& Engineering Chemistry Research 2012, 51, 1438-1463.

(5) Kock, E.-M.; Kogler, M.; Bielz, T.; Klatzer, B.; Penner, S. In Situ FT-IR Spectroscopic Study of CO2 and CO Adsorption on Y2O3, ZrO2, and Yttria-Stabilized ZrO2. The Journal of Physical Chemistry C 2013, 11\%, 17666-17673.

(6) Pacchioni, G. Physisorbed and chemisorbed CO2 at surface and step sites of the $\mathrm{MgO}(100)$ surface. Surface Science 1993, 281, 207 - 219.

(7) Polfus, J. M.; Yildiz, B.; Tuller, H. L.; Bredesen, R. Adsorption of CO2 and Facile Carbonate Formation on BaZrO3 Surfaces. The Journal of Physical Chemistry C 2018, 122, 307-314.

(8) Yang, C.-C.; Yu, Y.-H.; van der Linden, B.; Wu, J. C. S.; Mul, G. Artificial Photosynthesis over Crystalline TiO2-Based Catalysts: Fact or Fiction? Journal of the American Chemical Society 2010, 132, 8398-8406.

(9) Kotobuki, M.; Leppelt, R.; Hansgen, D.; Widmann, D.; Behm, R. Reactive oxygen on a Au/TiO2 supported catalyst. Journal of Catalysis 2009, 264, 67 - 76 . 
(10) Konova, P.; Naydenov, A.; Venkov, C.; Mehandjiev, D.; Andreeva, D.; Tabakova, T. Activity and deactivation of $\mathrm{Au} / \mathrm{TiO} 2$ catalyst in $\mathrm{CO}$ oxidation. Journal of Molecular Catalysis A: Chemical 2004, 213, $235-240$.

(11) Schumacher, B.; Denkwitz, Y.; Plzak, V.; Kinne, M.; Behm, R. Kinetics, mechanism, and the influence of $\mathrm{H} 2$ on the $\mathrm{CO}$ oxidation reaction on a $\mathrm{Au} / \mathrm{TiO} 2$ catalyst. Journal of Catalysis 2004, 224, $449-462$.

(12) Schubert, M. M.; Venugopal, A.; Kahlich, M. J.; Plzak, V.; Behm, R. Influence of H2O and $\mathrm{CO} 2$ on the selective $\mathrm{CO}$ oxidation in $\mathrm{H} 2$-rich gases over Au/a-Fe2O3. Journal of Catalysis 2004, 222, $32-40$.

(13) Daniells, S.; Overweg, A.; Makkee, M.; Moulijn, J. The mechanism of low-temperature $\mathrm{CO}$ oxidation with $\mathrm{Au} / \mathrm{Fe} 2 \mathrm{O} 3$ catalysts: a combined Mossbauer, FT-IR, and TAP reactor study. Journal of Catalysis 2005, 230, 52-65.

(14) Hakim, A.; Marliza, T. S.; Abu Tahari, N. M.; Wan Isahak, R. W. N.; Yusop, R. M.; Mohamed Hisham, W. M.; Yarmo, A. M. Studies on CO2 Adsorption and Desorption Properties from Various Types of Iron Oxides (FeO, Fe2O3, and Fe3O4). Industrial and Engineering Chemistry Research 2016, 55, 7888-7897.

(15) Wijnja, H.; Schulthess, C. ATR-FTIR and DRIFT spectroscopy of carbonate species at the aged y-Al2O3/water interface. Spectrochimica Acta Part A: Molecular and Biomolecular Spectroscopy 1999, 55, $861-872$.

(16) Auroux, A.; Gervasini, A. Microcalorimetric study of the acidity and basicity of metal oxide surfaces. The Journal of Physical Chemistry 1990, 94, 6371-6379.

(17) Freund, H.-J.; Roberts, M. Surface chemistry of carbon dioxide. Surface Science Reports 1996, $25,225-273$. 
(18) Montini, T.; Melchionna, M.; Monai, M.; Fornasiero, P. Fundamentals and Catalytic Applications of CeO2-Based Materials. Chemical Reviews 2016, 116, 5987-6041.

(19) Xu, C.; Qu, X. Cerium oxide nanoparticle: a remarkably versatile rare earth nanomaterial for biological applications. NPG Asia Materials 2014, 6, e90-e90.

(20) LIU, S.; WU, X.; WENG, D.; RAN, R. Ceria-based catalysts for soot oxidation: a review. Journal of Rare Earths 2015, 33, 567 - 590.

(21) Hernandez-Gimenez, A. M.; Lozano-Castello, D.; Bueno-Lopez, A. Effect of CO2, H2O and SO2 in the ceria-catalyzed combustion of soot under simulated diesel exhaust conditions. Applied Catalysis B: Environmental 2014, 148-149, 406 - 414.

(22) LeValley, T. L.; Richard, A. R.; Fan, M. The progress in water gas shift and steam reforming hydrogen production technologies a review. International Journal of Hydrogen Energy 2014, 39, 16983 - 17000.

(23) Capdevila-Cortada, M.; Vile, G.; Teschner, D.; Perez-Ramirez, J.; Lopez, N. Reactivity descriptors for ceria in catalysis. Applied Catalysis B: Environmental 2016, 197, 299 312.

(24) Lavoie, J.-M. Review on dry reforming of methane, a potentially more environmentallyfriendly approach to the increasing natural gas exploitation. Frontiers in Chemistry $2014,2,81$.

(25) Aramouni, N. A. K.; Touma, J. G.; Tarboush, B. A.; Zeaiter, J.; Ahmad, M. N. Catalyst design for dry reforming of methane: Analysis review. Renewable and Sustainable Energy Reviews 2018, 82, 2570 - 2585.

(26) Liu, X.; Ruettinger, W.; Xu, X.; Farrauto, R. Deactivation of Pt/CeO2 water-gas shift catalysts due to shutdown/startup modes for fuel cell applications. Applied Catalysis B: Environmental 2005, 56, $69-75$. 
(27) Kim, C. H.; Thompson, L. T. Deactivation of Au/CeOx water gas shift catalysts. Journal of Catalysis 2005, 230, 66 - 74.

(28) Deng, W.; Flytzani-Stephanopoulos, M. On the Issue of the Deactivation of Au-Ceria and Pt-Ceria Water-Gas Shift Catalysts in Practical Fuel-Cell Applications. Angewandte Chemie International Edition 2006, 45, 2285-2289.

(29) Cargnello, M.; Gentilini, C.; Montini, T.; Fonda, E.; Mehraeen, S.; Chi, M.; HerreraCollado, M.; Browning, N. D.; Polizzi, S.; Pasquato, L.; Fornasiero, P. Active and Stable Embedded AuCeO2 Catalysts for Preferential Oxidation of CO. Chemistry of Materials 2010, 22, 4335-4345.

(30) Hahn, K. R.; Iannuzzi, M.; Seitsonen, A. P.; Hutter, J. Coverage Effect of the CO2 Adsorption Mechanisms on CeO2(111) by First Principles Analysis. The Journal of Physical Chemistry C 2013, 117, 1701-1711.

(31) Cheng, Z.; Sherman, B. J.; Lo, C. S. Carbon dioxide activation and dissociation on ceria (110): A density functional theory study. The Journal of Chemical Physics 2013, $138,014702$.

(32) Wu, Z.; Li, M.; Overbury, S. H. On the structure dependence of CO oxidation over CeO2 nanocrystals with well-defined surface planes. Journal of Catalysis 2012, 285, $61-73$.

(33) Senanayake, S. D.; Mullins, D. R. Redox Pathways for HCOOH Decomposition over CeO2 Surfaces. The Journal of Physical Chemistry C 2008, 112, 9744-9752.

(34) Mullins, D. R.; Albrecht, P. M.; Chen, T.-L.; Calaza, F. C.; Biegalski, M. D.; Christen, H. M.; Overbury, S. H. Water Dissociation on CeO2(100) and CeO2(111) Thin Films. The Journal of Physical Chemistry C 2012, 116, 19419-19428. 
(35) Herman, G. S.; Kim, Y. J.; Chambers, S. A.; Peden, C. H. F. Interaction of D2O with CeO2(001) Investigated by Temperature-Programmed Desorption and X-ray Photoelectron Spectroscopy. Langmuir 1999, 15, 3993-3997.

(36) Senanayake, S. D.; Stacchiola, D.; Evans, J.; Estrella, M.; Barrio, L.; Perez, M.; Hrbek, J.; Rodriguez, J. A. Probing the reaction intermediates for the water-gas shift over inverse $\mathrm{CeOx} / \mathrm{Au}(111)$ catalysts. Journal of Catalysis 2010, 271, $392-400$.

(37) Albrecht, P. M.; Jiang, D.-e.; Mullins, D. R. CO2 Adsorption As a Flat-Lying, Tridentate Carbonate on CeO2(100). The Journal of Physical Chemistry C 2014, 118, 9042-9050.

(38) Kresse, G.; Hafner, J. Ab initio molecular-dynamics simulation of the liquid-metalamorphous-semiconductor transition in germanium. Phys. Rev. B 1994, 49, 1425114269.

(39) Kresse, G.; Furthmüller, J. Efficient iterative schemes for ab initio total-energy calculations using a plane-wave basis set. Phys. Rev. B 1996, 54, 11169-11186.

(40) Dudarev, S. L.; Botton, G. A.; Savrasov, S. Y.; Humphreys, C. J.; Sutton, A. P. Electron-energy-loss spectra and the structural stability of nickel oxide: An LSDA+U study. Phys. Rev. B 1998, 57, 1505-1509.

(41) Molinari, M.; Parker, S. C.; Sayle, D. C.; Islam, M. S. Water Adsorption and Its Effect on the Stability of Low Index Stoichiometric and Reduced Surfaces of Ceria. The Journal of Physical Chemistry C 2012, 116, 7073-7082.

(42) Symington, A.; Molinari, M.; Moxon, S.; Flitcroft, J.; Sayle, D.; Parker, S. C. Strongly Bound Surface Water Affects the Shape Evolution of Cerium Oxide Nanoparticles. 2019 , 
(43) Nolan, M.; Grigoleit, S.; Sayle, D. C.; Parker, S. C.; Watson, G. W. Density functional theory studies of the structure and electronic structure of pure and defective low index surfaces of ceria. Surface Science 2005, 576, 217 - 229.

(44) Nolan, M.; Parker, S. C.; Watson, G. W. Reduction of NO2 on Ceria Surfaces. The Journal of Physical Chemistry B 2006, 110, 2256-2262.

(45) Watson, G. W.; Parker, S. C.; Kresse, G. Ab initio calculation of the origin of the distortion of $\alpha$-PbO. Phys. Rev. B 1999, 59, 8481-8486.

(46) Oliver, P. M.; Parker, S. C.; Mackrodt, W. C. Computer simulation of the crystal morphology of NiO. Modelling and Simulation in Materials Science and Engineering 1993, 1,755 .

(47) Molinari, M.; Symington, A. R.; Sayle, D. C.; Sakthivel, T. S.; Seal, S.; Parker, S. C. Computer-Aided Design of Nanoceria Structures as Enzyme Mimetic Agents: The Role of Bodily Electrolytes on Maximizing Their Activity. ACS Applied Bio Materials 2019, 2, 1098-1106.

(48) Nolan, M.; Parker, S. C.; Watson, G. W. The electronic structure of oxygen vacancy defects at the low index surfaces of ceria. Surface Science 2005, 595, 223 - 232.

(49) Tegner, B. E.; Molinari, M.; Kerridge, A.; Parker, S. C.; Kaltsoyannis, N. Water Adsorption on AnO2 111, 110, and 100 Surfaces $(\mathrm{An}=\mathrm{U}$ and $\mathrm{Pu})$ : A Density Functional Theory + U Study. The Journal of Physical Chemistry C 2017, 121, 1675-1682.

(50) Symington, A.; Tse, J.; Molinari, M.; Marmier, A.; Parker, S. surfinpy: A Surface Phase Diagram Generator. Journal of Open Source Software 2019, 4, 1210.

(51) Tran, R.; Xu, Z.; Radhakrishnan, B.; Winston, D.; Sun, W.; Persson, K. A.; Ong, S. P. Surface energies of elemental crystals. Scientific Data 2016, 3, 160080. 
(52) Momma, K.; Izumi, F. VESTA3 for three-dimensional visualization of crystal, volumetric and morphology data. Journal of Applied Crystallography 2011, 44, 1272-1276.

(53) Sun, Q.; Reuter, K.; Scheffler, M. Effect of a humid environment on the surface structure of RuO2(110). Phys. Rev. B 2003, 67, 205424.

(54) Kerisit, S.; Marmier, A.; Parker, S. C. Ab Initio Surface Phase Diagram of the 1014 Calcite Surface. The Journal of Physical Chemistry B 2005, 109, 18211-18213.

(55) Staudt, T.; Lykhach, Y.; Tsud, N.; Skala, T.; Prince, K.; Matolin, V.; Libuda, J. Ceria reoxidation by CO2: A model study. Journal of Catalysis 2010, 275, 181 - 185.

(56) Feng, Z. A.; Machala, M. L.; Chueh, W. C. Surface electrochemistry of CO2 reduction and $\mathrm{CO}$ oxidation on Sm-doped $\mathrm{CeO} 2-\mathrm{x}$ : coupling between $\mathrm{Ce} 3+$ and carbonate adsorbates. Phys. Chem. Chem. Phys. 2015, 17, 12273-12281.

(57) Castanet, U.; Feral-Martin, C.; Demourgues, A.; Neale, R. L.; Sayle, D. C.; Caddeo, F.; Flitcroft, J. M.; Caygill, R.; Pointon, B. J.; Molinari, M.; Majimel, J. Controlling the 111/110 Surface Ratio of Cuboidal Ceria Nanoparticles. ACS Applied Materials \& Interfaces 2019, 11, 11384-11390.

(58) Desaunay, T.; Bonura, G.; Chiodo, V.; Freni, S.; Couzinie, J.-P.; Bourgon, J.; Ringuede, A.; Labat, F.; Adamo, C.; Cassir, M. Surface-dependent oxidation of H2 on CeO2 surfaces. Journal of Catalysis 2013, 297, 193 - 201.

(59) Sudarsanam, P.; Hillary, B.; Deepa, D. K.; Amin, M. H.; Mallesham, B.; Reddy, B. M.; Bhargava, S. K. Highly efficient cerium dioxide nanocube-based catalysts for low temperature diesel soot oxidation: the cooperative effect of cerium- and cobalt-oxides. Catal. Sci. Technol. 2015, 5, 3496-3500.

(60) Yi, G.; Xu, Z.; Guo, G.; ichi Tanaka, K.; Yuan, Y. Morphology effects of nanocrystalline 
$\mathrm{CeO} 2$ on the preferential $\mathrm{CO}$ oxidation in $\mathrm{H} 2$-rich gas over $\mathrm{Au} / \mathrm{CeO} 2$ catalyst. Chemical Physics Letters 2009, 479, $128-132$.

(61) Yi, G.; Yang, H.; Li, B.; Lin, H.; ichi Tanaka, K.; Yuan, Y. Preferential CO oxidation in a $\mathrm{H} 2$-rich gas by $\mathrm{Au} / \mathrm{CeO} 2$ catalysts: Nanoscale $\mathrm{CeO} 2$ shape effect and mechanism aspect. Catalysis Today 2010, 157, 83 - 88, 6th World Congress on Oxidation Catalysis Lille, France, 5-10 July 2009 Towards an integrated approach in innovation and development.

(62) Monte, M.; Gamarra, D.; Camara, A. L.; Rasmussen, S.; Gyorffy, N.; Schay, Z.; Martnez-Arias, A.; Conesa, J. Preferential oxidation of $\mathrm{CO}$ in excess $\mathrm{H} 2$ over $\mathrm{CuO} / \mathrm{CeO} 2$ catalysts: Performance as a function of the copper coverage and exposed face present in the $\mathrm{CeO} 2$ support. Catalysis Today 2014, 229, 104 - 113, Advances in the use of X-rays for the characterization of functional catalytic materials. 